\title{
VOLUME REDUCTION OF THE NATIVE LUNG AFTER SINGLE-LUNG TRANSPLANTATION FOR EMPHYSEMA
}

\author{
David P. Kapelanski, MD, ${ }^{a}$ Mark B. Anderson, MD, ${ }^{\text {a }}$ Jolene M. Kriett, MD, ${ }^{\text {a }}$ Henri G. Colt, MD, \\ Cecilia M. Smith, MD, ${ }^{\mathrm{b}}$ Manuel Mateos, MD, and Stuart W. Jamieson, MB, ${ }^{a}$ San Diego, Calif.
}

Emphysema is currently the most frequent indication for single-lung transplantation. A decade ago, however, it was postulated that after single-lung transplantation the emphysematous contralateral lung would be preferentially ventilated, with consequent mediastinal shift and compression of the graft. Conversely, the attenuated capillary bed of the diseased lung would necessitate preferential perfusion of the graft. ${ }^{1}$ The theoretic prospect of wholesale ventilation-perfusion mismatch has not been a significant concern in clinical practice, and during this period the combination of ongoing restrictions in the donor pool, the accumulation of excellent functional outcomes after unilateral transplantation, and the higher operative morbidity associated with bilateral procedures has compelled increasing use of single-lung transplantation for the management of end-stage emphysema. Because graft function is the preeminent factor when pulmonary mechanics and gas exchange are assessed at successively remote intervals after single-lung transplantation, the fate of the retained native lung has not been well summarized, and we are unaware of any series describing the discrete effects of the residual emphysematous lung on pulmonary allograft function. We present a case of progressive pulmonary dysfunction associated with marked hyperinflation of the native lung in a single-lung recipient, with successful management by a unilateral volume-reduction operation.

One of us (M. M.) underwent a right single-lung transplant for emphysema in 1991, and after an uneventful postoperative course was able to resume his medical practice. Within 3 years, however, dyspnea and exercise intolerance recurred. There was no improvement despite treatment of a concurrent infection, and empirical augmentation of the immunosuppressive regimen afforded only transient relief. Supplemental oxygen was administered at rest and during exercise. The chest radiograph demonstrated marked hyperinflation of the native lung, with mediastinal displacement and depression of the left hemidiaphragm (Fig. 1, $A$ ). Consecutive pulmonary function studies documented serial reductions in expiratory flow and vital capacity while residual volume and functional residual capacity were concurrently expanding ( $\mathrm{Ta}-$ ble I). Volume reduction of the native lung was proposed as an alternative to retransplantation.

From the Divisions of Cardiothoracic Surgery ${ }^{\mathrm{a}}$ and Pulmonary Medicine, ${ }^{b}$ School of Medicine, The University of California, San Diego, 200 West Arbor Dr., San Diego, CA 92103-8892.

Received for publication July 27, 1995; accepted for publication August 9, 1995.

J Thorac Cardiovasc Surg 1996;111:898-9

Copyright $(\mathcal{C} 1996$ by Mosby-Year Book, Inc.

$0022-5223 / 96 \$ 5.00+0 \quad \mathbf{1 2 / 5 4 / 6 8 5 5 6}$
A muscle-sparing left thoracotomy revealed generalized emphysema of the native lung, with several dominant bullae in the upper lobe and superior segment of the lower lobe. Regional air trapping was demonstrated during operation by repeated deflation and inflation of the left lung, and pneumectomy was accomplished by means of a linear stapler reinforced with bovine pericardial strips. ${ }^{2}$ Unassisted ventilation was resumed at completion of the procedure. A constant low-volume air leak sealed after 14 days of pleural drainage, and recovery was otherwise routine. The postoperative radiographs demonstrated reduced inflation of the native lung, with reciprocal expansion of the allograft and restoration of a normal diaphragmatic contour (Fig. 1, B). Symptomatic improvement has been ongoing during the initial 3 months, and expiratory flow is now superior to that recorded at the same interval after transplantation (Table I). Supplemental oxygen is no longer required.

The natural history of patients with emphysema is well characterized. $^{3}$ Once initiated, the process of alveolar destruction and acinar coalescence appears irreversible, and we are not aware of any data indicating that singlelung transplantation in any way modifies the progression of the disease in the retained lung. To the contrary, the initial improvement in pulmonary mechanics observed after single-lung replacement for emphysema has not generally been sustained, and it has been suggested that in younger patients with emphysema the bilateral procedure may prove more durable, although at the cost of a higher perioperative risk.

Excluding septic complications, late clinical deterioration in the lung recipient is generally attributable to the development of the bronchiolitis obliterans syndrome, which is characterized by a progressive decline in forced expiratory volume that often manifests before the recurrence of symptoms. If other causes of reduced airflow are excluded after conventional chest radiography, computed tomography, and bronchoscopy, the diagnosis is presumed even in the absence of histologic confirmation. ${ }^{4}$ The management of bronchiolitis obliterans generally combines an incrementation of maintenance immunosuppression after administration of either steroid pulses or cytolytic therapy, but recovery of function has generally been evanescent and even transient stabilization of mechanics at reduced but tolerable levels has been achieved inconsistently. If augmented immunosuppression fails to arrest the process, repeated transplantation has been employed to salvage selected patients considered to have favorable risks, but most die of respiratory failure or opportunistic infection engendered by aggressive immunosuppression.

The subject of this report fulfills the consensus criteria for grade $2 \mathrm{~A}$ bronchiolitis obliterans syndrome 

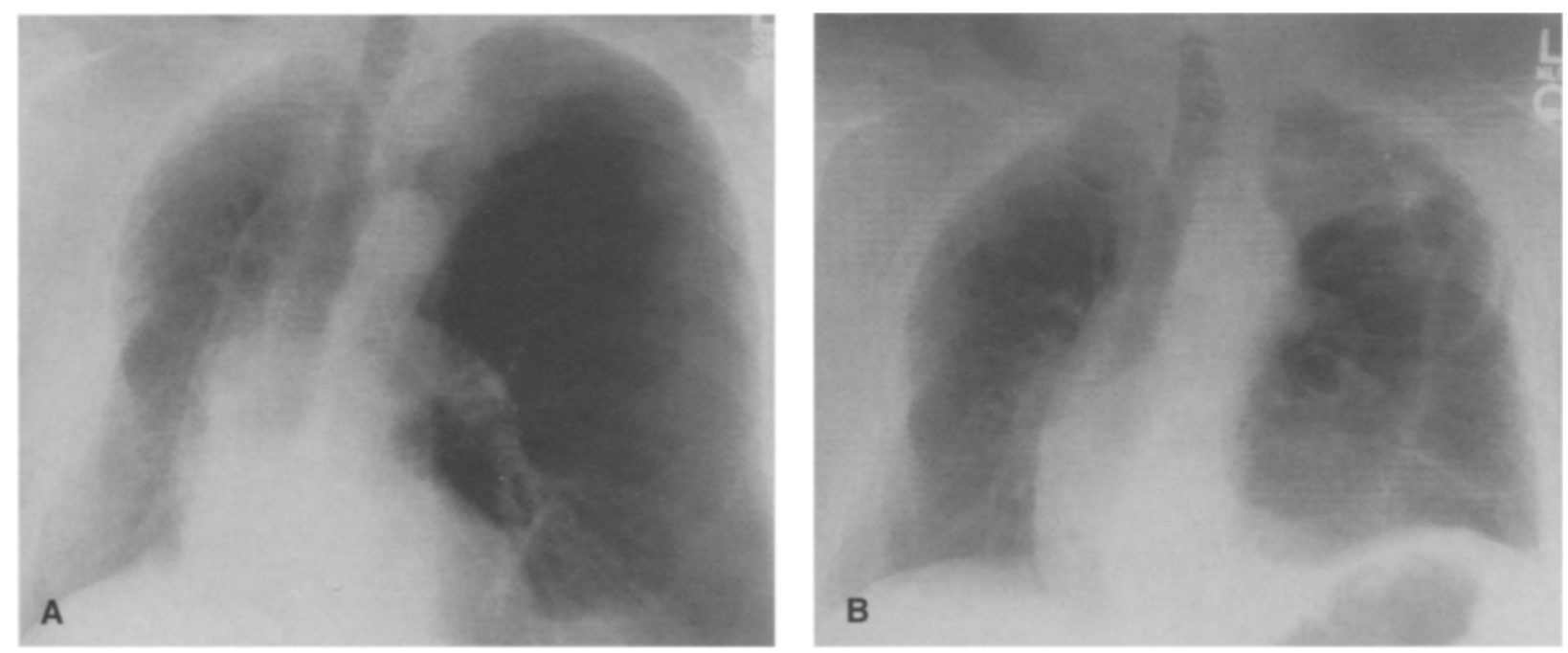

Fig. 1. A, Posteroanterior radiograph 36 months after right single-lung transplantation demonstrates hyperinflation of the left lung, with mediastinal shift and compression of the right lung allograft. B, Posteroanterior radiograph 1 month after left pneumectomy demonstrates a reduction in mediastinal shift, restoration of the contour of the left hemidiaphragm, and reciprocal expansion of the allograft.

Table I. Pulmonary function studies

\begin{tabular}{|c|c|c|c|c|c|c|c|c|c|c|c|c|c|c|}
\hline & \multicolumn{2}{|c|}{$\begin{array}{c}\text { Before } \\
\text { transplantation }\end{array}$} & \multicolumn{2}{|c|}{$\begin{array}{l}3 \text { Months after } \\
\text { transplantation }\end{array}$} & \multicolumn{2}{|c|}{$\begin{array}{l}12 \text { Months after } \\
\text { transplantation }\end{array}$} & \multicolumn{2}{|c|}{$\begin{array}{l}24 \text { Months after } \\
\text { transplantation }\end{array}$} & \multicolumn{2}{|c|}{$\begin{array}{l}36 \text { Months after } \\
\text { transplantation }\end{array}$} & \multicolumn{2}{|c|}{$\begin{array}{c}1 \text { Month after } \\
\text { pneumonectomy }\end{array}$} & \multicolumn{2}{|c|}{$\begin{array}{l}3 \text { Months after } \\
\text { pneumonectom }\end{array}$} \\
\hline & Value & $\begin{array}{c}\% \\
\text { Predicted }\end{array}$ & Value & $\begin{array}{c}\% \\
\text { Predicted }\end{array}$ & Value & $\begin{array}{c}\% \\
\text { Predicted }\end{array}$ & Value & $\begin{array}{c}\% \\
\text { Predicted }\end{array}$ & Value & $\begin{array}{c}\% \\
\text { Predicted }\end{array}$ & Value & $\begin{array}{c}\% \\
\text { Predicted }\end{array}$ & Value & $\begin{array}{c}\% \\
\text { Predicted }\end{array}$ \\
\hline $\mathrm{FEV}_{1}(\mathrm{~L})$ & 0.57 & 19 & 1.58 & 53 & 1.22 & 41 & 1.33 & 44 & 0.89 & 30 & 1.54 & 52 & 1.77 & 60 \\
\hline FVC (L) & 2.55 & 60 & 2.58 & 61 & 2.22 & 52 & 2.44 & 57 & 1.28 & 30 & 2.32 & 55 & 2.63 & 62 \\
\hline $\mathrm{FEV}_{1} / \mathrm{FVC}(\%)$ & 22 & & 61 & & 55 & & 54 & & 70 & & 67 & & 67 & \\
\hline $\mathrm{FRC}(\mathrm{L})$ & 8.35 & 246 & 4.61 & 140 & 4.84 & 153 & 4.98 & 148 & 5.16 & 154 & 2.08 & 64 & 2.53 & 79 \\
\hline RV (L) & 7.29 & 326 & 4.12 & 183 & 4.00 & 178 & 4.61 & 203 & 4.99 & 217 & 1.55 & 67 & 1.92 & 83 \\
\hline TLC (L) & 9.84 & 160 & 6.92 & 113 & 6.56 & 108 & 7.42 & 121 & 6.77 & 111 & 3.98 & 65 & 4.79 & 78 \\
\hline
\end{tabular}

$F E V_{1}$, Forced expiratory volume in 1 second; $F V C$, forced vital capacity; $F R C$, functional residual capacity; $R V$, residual volume; $T L C$, total lung capacity.

(forced expiratory volume in 1 second $51 \%$ to $65 \%$ of baseline value without histologic confirmation). ${ }^{4}$ Even in retrospect, however, preoperative assessment does not permit an unequivocal assignment of the extent of dysfunction attributable to progressive compression of the graft by the emphysematous lung or the evolution of bronchiolitis obliterans in the graft. If the initial improvement in mechanics reported here is sustained on future evaluations, precise discrimination among the two possibilities and combinations thereof might be ignored from a pragmatic perspective. Unilateral volume reduction for late airflow reduction after singlelung transplantation for emphysema may allow restoration of satisfactory mechanics in selected patients.

\section{REFERENCES}

1. Kaiser LR, Cooper JD, Trulock EP, Pasque MK, Triantafillou AN, Haydock D. The evolution of single lung transplant for emphysema. J Thorac Cardiovasc Surg 1991;102:333-41.

2. Cooper JD, Trulock EP, Triantafillou AN, et al. Bilateral pneumectomy (volume reduction) for chronic obstructive pulmonary disease. J THORAC CARDIOVASC SuRg 1995;109:106-19.

3. Turino GM. Natural history and clinical management of emphysema in patients with and without alpha 1-antitrypsin deficiency. Ann N Y Acad Sci 1991;624:18-29.

4. Cooper JD, Billingham ME, Egan T, et al. A working formulation for the standardization of nomenclature and for clinical staging of chronic dysfunction in lung allografts. J Heart Lung Transplant 1993;12:713-6. 